OPEN ACCESS

Edited by:

Xavier Noel,

Free University of Brussels, Belgium

Reviewed by:

Serge Brand,

Universität Basel, Switzerland

Xiaowei Han,

China-Japan Friendship Hospital,

China

*Correspondence:

Nian-Sheng Tzeng

pierrens@mail.ndmctsgh.edu.tw; pierrens91@gmail.com

Specialty section

This article was submitted to

Psychopathology,

a section of the journal

Frontiers in Psychiatry

Received: 21 May 2018

Accepted: 07 August 2018 Published: 07 September 2018

Citation:

Chu C-W, Chien W-C, Chung C-H, Chao P-C, Chang H-A, Kao Y-C, Chou Y-C and Tzeng N-S (2018) Electroconvulsive Therapy and Risk of

Dementia-A Nationwide Cohort Study in Taiwan.

Front. Psychiatry 9:397. doi: 10.3389/fpsyt.2018.00397

\section{Electroconvulsive Therapy and Risk of Dementia-A Nationwide Cohort Study in Taiwan}

\author{
Ching-Wen Chu ${ }^{1}$, Wu-Chien Chien ${ }^{2,3,4}$, Chi-Hsiang Chung ${ }^{3,4,5}$, Pei-Chun Chao ${ }^{1}$, \\ Hsin-An Chang ${ }^{1,6}$, Yu-Chen Kao ${ }^{1}$, Yu-Ching Chou ${ }^{3}$ and Nian-Sheng Tzeng ${ }^{1,6 *}$
}

' Department of Psychiatry, Tri-Service General Hospital, School of Medicine, National Defense Medical Center, Taipei, Taiwan, ${ }^{2}$ Department of Medical Research, Tri-Service General Hospital, National Defense Medical Center, Taipei, Taiwan, ${ }^{3}$ School of Public Health, National Defense Medical Center, Taipei, Taiwan, ${ }^{4}$ Institute of Life Sciences, National Defense Medical Center, Taipei, Taiwan, ${ }^{5}$ Taiwanese Injury Prevention and Safety Promotion Association, Taipei, Taiwan, ${ }^{6}$ Student Counseling Center, National Defense Medical Center, Taipei, Taiwan

Background: Electroconvulsive therapy (ECT) is an effective treatment for schizophrenia, bipolar disorder, and major depressive disorder, and a temporary memory loss may occur after ECT. However, the association between ECT in patients with schizophrenia, bipolar disorder, and major depressive disorder, and the risk of dementia is yet to be examined.

Objective: This study aimed to clarify as to whether ECT is associated with the risk of dementia after ECT in patients with schizophrenia, bipolar disorder, and major depressive disorder, using Taiwan's National Health Insurance Research Database (NHIRD).

Methods: A total of 3,796 enrolled participants (schizophrenia, 46.68\%; bipolar disorder, 11.77\%; and major depressive disorder, 41.55\%) with 994 patients who had received ECT and 2,982 controls matched for sex and age, between January 1, and December 31, 2000, were selected from the NHIRD. After adjusting for confounding factors, Fine and Gray's survival analysis was used to compare the risk of developing dementia during the 10 years of follow-up.

Results: Of the study patients, 45 (4.53\%) of them developed dementia when compared to $149(5.0 \%)$ in the control group. Fine and Gray's survival analysis revealed that the study patients were not associated with an increased risk of dementia [hazard ratio $(\mathrm{HR})=0.612,95 \%$ confidence interval $(\mathrm{Cl})=0.438-1.854, P=0.325]$. After adjusting for sex, age, monthly income, urbanization level, geographic region, and comorbidities, the adjusted $\mathrm{HR}$ was $0.633(95 \% \mathrm{Cl}=0.448-1.895, P=0.304)$.

Conclusion: This study supports that ECT was not associated with the increased risk of dementia in patients with schizophrenia, bipolar disorder, and major depressive disorder, using the NHIRD.

Keywords: electroconvulsive therapy, cohort study, National Health Insurance Research Database, dementia, risk 


\section{INTRODUCTION}

Electroconvulsive therapy (ECT) is an effective treatment for major mental illnesses. ECT is relatively safe and with absolutely no medical contraindications $(1,2)$. The adverse events and complications are also concerns for the ECT. Moreover, a few complications have been reported in patients undergoing ECT, for example, prolonged seizures (3) and fractures (4). Low death rates were also noted in the ECT (5-8). A short period of memory loss was one of the remarkable complications, which could last as long as several months after the ECT (9-11).

Dementia is a growing global health problem (12-14), which results in a burden for the patient, caregivers, and society (1517). Since the short period of memory loss, as aforementioned, and amnesia could be the risk factors of subsequent cognitive disorders, including dementia $(2,18-21)$, it is therefore necessary to examine as to whether ECT is associated with an increase in subsequent dementia.
One Danish cohort study reported that the ECT is not associated with the risk of dementia in patients with affective disorders (22). However, further study is crucial to clarify as to whether there is an association between the ECT in patients with schizophrenia, bipolar disorder, major depressive disorders, and dementia. We therefore aimed to study any incidence of the risk of dementia, prolonged seizures, bone fractures, and death rates from ECT, utilizing the National Health Insurance Research Database (NHIRD) in Taiwan.

\section{MATERIALS AND METHODS \\ Data Sources}

In this study, we used data from the NHIRD to investigate the association between the patients who have received ECT and developed dementia over a 10 -year follow-up period, from the outpatient and hospitalization Longitudinal Health Insurance Database (LHID) (2000-2010). In 1995, the National Health

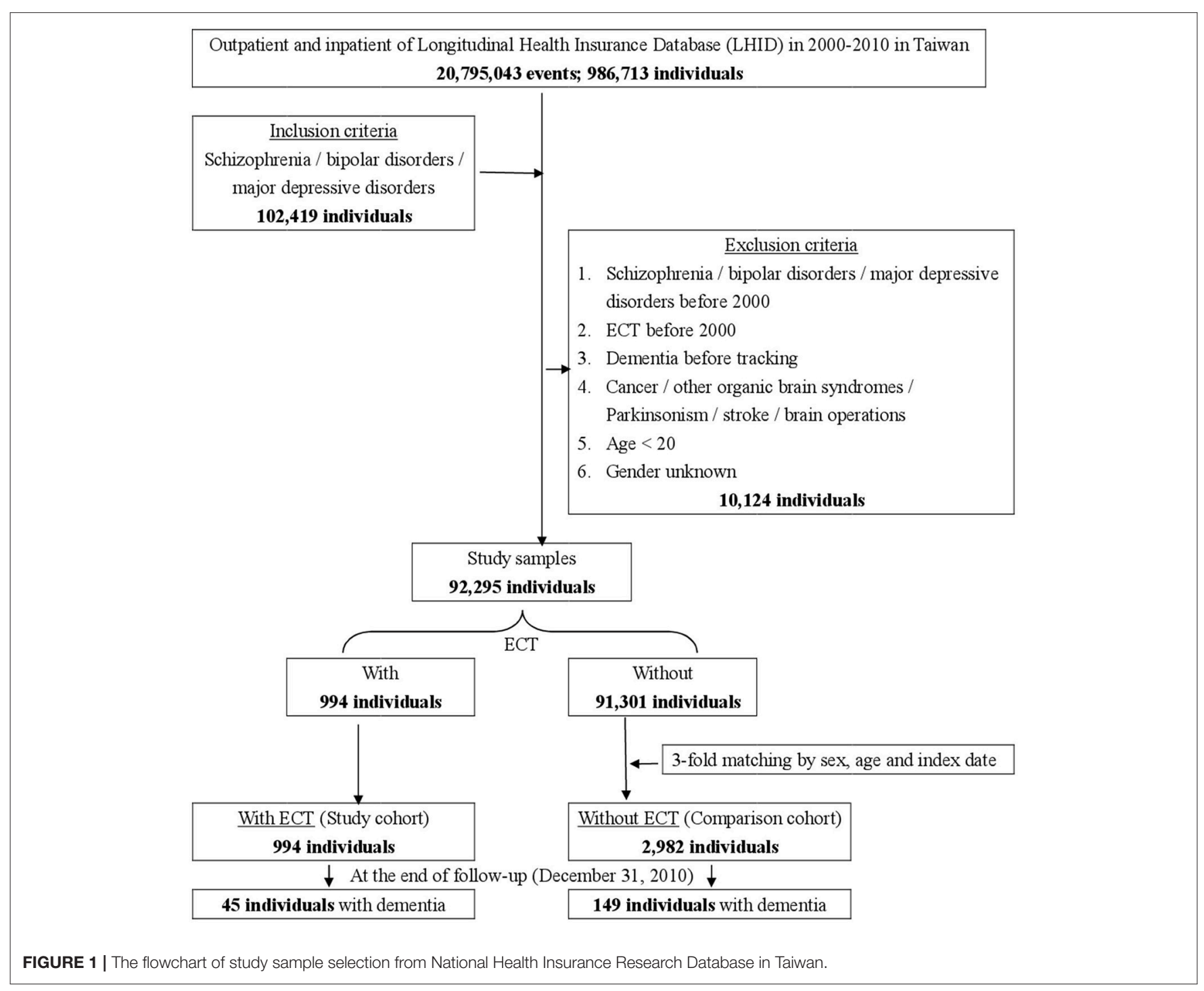


Insurance (NHI) Program was launched, which had contracts with $97 \%$ of the medical providers, and enrolled more than $99 \%$ of the 23 million population as of June, 2009 (23). The NHIRD includes comprehensive data on the inpatient care, ambulatory care, dental care, and prescription drugs availed by the insurees, as well as their sex and date of birth. Pursuant to the Personal Information Protection Act, individual identifiers are encrypted before release for research. The diagnoses recorded in the NHIRD are coded according to the International Classification of Disease, Ninth Revision, Clinical Modification (ICD-9-CM) (24). The details of the program have been documented in the previous studies (16, 20, 25-29).

All diagnoses of dementia were made by board-certified psychiatrists or neurologists, and for the patients who received ECT, we focused on schizophrenia, bipolar disorders, and major depressive disorders, and all these diagnoses were made by board-certified psychiatrists. The NHI Administration randomly reviews the records of the ambulatory care visits and the inpatient claims, to verify the accuracy of the diagnoses (30). Several studies have demonstrated the accuracy and validity of the diagnoses in the NHIRD (31-33). Therefore, it is suitable to use the NHIRD as the correct tool to complete this study. The ethical committee, Institutional Review Board of the Tri-Service General Hospital, approved this study (TSGH IRB No. 1-104-05-145).

\section{Study Design and Sampled Participants}

This study was of a retrospective, matched-cohort design. Patients with schizophrenia, bipolar disorders, or major depressive disorders, who had received ECT, were selected from January 1, to December 31, 2000, according to ICD-9-CM codes: ICD-9-CM 314. In addition, each enrolled patient was required to have made at least three outpatient visits within the 1-year study period for dementia, according to these ICD-9-CM codes. The patients diagnosed with schizophrenia, bipolar disorders, or major depressive disorders before 2000, and the patients who had received ECT before 2000, were excluded. Patients with cancer (ICD-9-CM codes: 140-208), other organic brain syndromes (ICD-9-CM codes: 294), Parkinsonism (ICD-9-CM codes: 332), stroke (ICD-9-CM codes: 430-434), and a history of brain surgeries (ICD-9-CM codes: OP01-OP04) were also excluded. In addition, all the patients aged $<20$ years were also excluded. A total of 3,796 enrolled participants (schizophrenia, 46.68\%; bipolar disorder, 11.77\%; and major depressive disorders, $41.55 \%$ ), with 994 patients who had received ECT, and 2,982 controls (1:3) matched for sex and age, between January 1, and December 31, 2000, were selected from the NHIRD (Figure 1).

\section{Covariates}

The covariates included sex, age groups (those aged 20-64 and $\geqq 65$ years), geographical area of residence (north, center, south, and east of Taiwan), urbanization level of residence (levels 14), and insurance premiums (in New Taiwan Dollars (NT\$); $<18,000,18,000-34,999, \geq 35,000)$. The urbanization level of residence was defined according to the population and various indicators of the level of development. Level 1 was defined as a population of $>1,250,000$, and a specific designation as political, economic, cultural, and metropolitan development. Level 2 was defined as a population between 500,000 and 1,249,999, and as playing an important role in the political system, economy, and culture. Urbanization levels 3 and 4 were defined as a population between 149,999 and 499,999, and <149,999, respectively (34). The Charlson comorbidity index was used to adjust the factors of the comorbidities (35). Post-ECT prolonged seizures, inhospital delirium, major cardiovascular adverse events (MACE's), including, acute myocardial infarction (AMI), acute stroke, coronary artery disease (CAD), dysrhythmia, cardiac shock, and deaths within the hospital stay in which the ECT was used, were recorded.

\section{Major Outcome}

Data on all of the study participants were collected for the time period beginning January 1, to December 31, 2000, until the onset

\begin{tabular}{|c|c|c|c|c|c|}
\hline \multirow{2}{*}{$\begin{array}{l}\text { ECT } \\
\text { variables }\end{array}$} & \multicolumn{2}{|c|}{ With } & \multicolumn{2}{|c|}{ Without } & \multirow[t]{2}{*}{$P$} \\
\hline & $n$ & $\%$ & $n$ & $\%$ & \\
\hline Total & 994 & 25.00 & 2,982 & 75.00 & \\
\hline Study sample subgroup & & & & & 0.999 \\
\hline Schizophrenia & 464 & 46.68 & 1,392 & 46.68 & \\
\hline Bipolar disorders & 117 & 11.77 & 351 & 11.77 & \\
\hline Major depressive disorders & 413 & 41.55 & 1,239 & 41.55 & \\
\hline Gender & & & & & 0.999 \\
\hline Male & 380 & 38.23 & 1,140 & 38.23 & \\
\hline Female & 614 & 61.77 & 1,842 & 61.77 & \\
\hline Age (years) & \multicolumn{2}{|c|}{$39.65 \pm 12.76$} & \multicolumn{2}{|c|}{$40.40 \pm 13.30$} & 0.506 \\
\hline Age group (years) & & & & & 0.999 \\
\hline $20-64$ & 960 & 96.58 & 2,880 & 96.58 & \\
\hline$\geqq 65$ & 34 & 3.42 & 102 & 3.42 & \\
\hline CCl_R & \multicolumn{2}{|c|}{$0.13 \pm 0.29$} & \multicolumn{2}{|c|}{$0.18 \pm 0.55$} & 0.643 \\
\hline Urbanization level & & & & & $<0.001$ \\
\hline 1 (The highest) & 493 & 49.60 & 894 & 29.98 & \\
\hline 2 & 418 & 42.05 & 1,294 & 43.39 & \\
\hline 3 & 51 & 5.13 & 307 & 10.30 & \\
\hline 4 (The lowest) & 32 & 3.22 & 487 & 16.33 & \\
\hline Location & & & & & $<0.001$ \\
\hline Northern Taiwan & 430 & 43.26 & 1,217 & 40.81 & \\
\hline Middle Taiwan & 218 & 21.93 & 754 & 25.29 & \\
\hline Southern Taiwan & 336 & 33.80 & 727 & 24.38 & \\
\hline Eastern Taiwan & 9 & 0.91 & 264 & 8.85 & \\
\hline Outlets islands & 1 & 0.10 & 20 & 0.67 & \\
\hline Insured premium (NT\$) & & & & & 0.860 \\
\hline$<18,000$ & 984 & 98.99 & 2,947 & 98.83 & \\
\hline $18,000-34,999$ & 9 & 0.91 & 30 & 1.01 & \\
\hline$\geqq 35,000$ & 1 & 0.10 & 5 & 0.17 & \\
\hline
\end{tabular}

$P$, Chi-square/Fisher exact test on category variables and t-test on continue variables; CCl, Charlson Comorbidity Index; NT\$, New Taiwan Dollars. 
of dementia (ICD-9-CM codes: 290.0, 290.10, 290.11, 290.12, 290.13, 290.20, 290.21, 290.3, 290.41, 290.42, 290.43, 290.8, 290.9, and 331.0), withdrawal from the NHI program, or the end of 2010. The dementia could be denoted as Alzheimer-type dementia (AD, 290.0x-290.3x, and 331.0), vascular dementia (VaD, 290.4), and other dementias (290.9). In this study, cases of dementia were defined by the criteria of Diagnostic and Statistical Manual of Mental Disorders, Fourth Edition, Text Revision (DSM-IV-TR), and recorded by the ICD-9-CM codes as aforementioned. These cases stand for a significant impairment in social or occupational functioning, and represent a significant decline from a previous level of functioning by memory impairment, and one or more of the following cognitive disturbances such as aphasia, apraxia, agnosia and disturbance in executive functioning. The types of $\mathrm{AD}, \mathrm{VaD}$, and other dementia are also defined by the DSM-IV-TR (36).

\section{Statistical Analyses}

For the baseline, and the end of the follow-up of the demographic characteristics of the study population, we applied the Chi-square and Fisher exact test for the categorical variability, and a $t$-test for the continual variability. For the survival analysis of the factors of dementia, we used the Kaplan-Meier analysis for the cumulative risk of the follow-up. For each of the dementia analysis factors, the Fine and Gray's competing risk model with both crude hazard ratio (HR) and adjusted HR was applied. Each significant factor and subgroup of dementia type were stratified by using either the Cox regression or Fine and Gray's competing risk model, along with the crude and adjusted HR which were also included for further analysis. All the tests were two-sided, and $p<0.05$ was considered statistically significant. All the statistical analyses were performed using the IBM SPSS Statistics for Windows, Version 22.0 (IBM Corp., Armonk, NY, USA).

\section{RESULTS}

\section{Baseline Characteristics of the Study Population}

Table 1 shows the sex, age, psychiatric disorder groups, CCI, urbanization and area of residence, and the insurance premiums of the study patients and controls. There were no differences between the study patients and the control groups in sex, age, psychiatric disorder groups, CCI, and insurance premiums. When compared to the non-ECT controls, the ECT cohort tended to live in higher urbanized regions, and in the northern and central regions of Taiwan $(p<0.001)$.

Supplementary Table 1 depicts the comparison of the three diagnoses - schizophrenia, bipolar disorder, and major

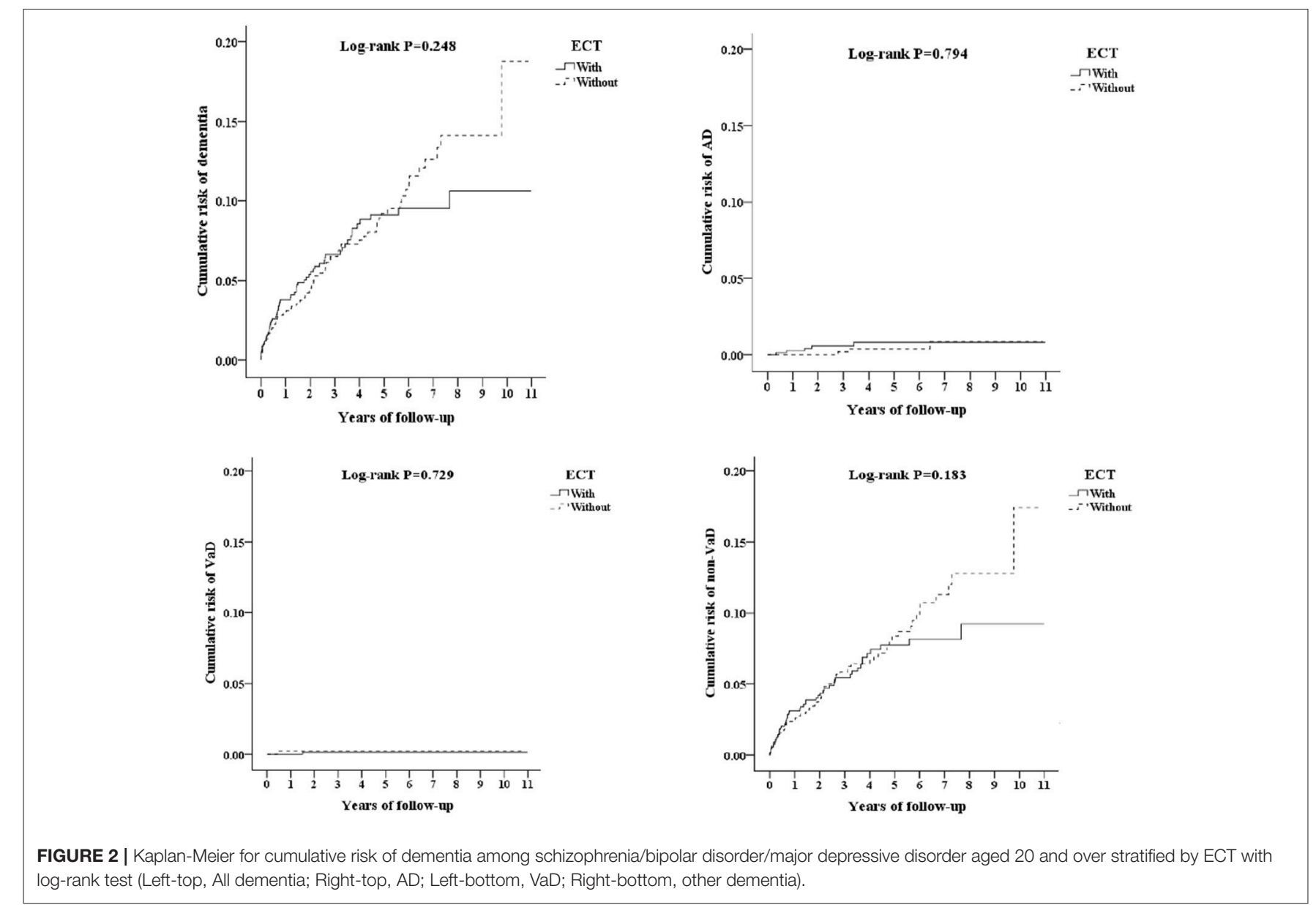


depressive disorder. There were more female patients in the groups of bipolar disorder and major depressive disorder. There were also marginal significant differences in the urbanization levels and residence areas in Taiwan among these three diagnostic groups.

\section{Kaplan-Meier Model for the Cumulative Risk of Dementia}

Figure 2 depicts the Kaplan-Meier analysis for the cumulative incidence of dementia in the study and control groups, and there were no differences between the two groups as being statistically significant, in overall $\mathrm{AD}, \mathrm{VaD}$, and other dementia.

\section{Comparisons of the Dementia, ECT-Related Complications at the End of Study, and the Readmission Rates After ECT-Related Hospitalizations}

Table 2 shows that at the end of the follow-up, 45 out of 994 patients in the study group (4.53\%), and 149 out of 2,982 (5.00\%) patients in the control group developed dementia. There were only marginal differences in prolonged seizures and in-hospital delirium between the ECT and non-ECT cohorts. In this 10-year follow-up period, none of the study subjects or the control group died.

Supplementary Table 2 depicts the hospital re-admission rates. In these three diagnostic groups, the overall re-admission rates and rates of re-admission for ECT were more than 80 and $20 \%$, respectively.

\section{Hazard Ratios Analysis of Dementia in the Patients Who Received ECT}

Table 3 shows the results of Fine and Gray's survival analysis of the factors associated with the risk of developing dementia. Fine and Gray's survival analysis revealed that the ECT cohort were not more likely to develop dementia, and after adjusting for sex, age, monthly income, urbanization level, geographic region, and comorbidities, the adjusted HR was 0.992 (95\% CI $=0.896-$ $1.099, p=0.882$ ). For the male patients older than 65 years, and the ECT cohort with prolonged seizures, in-hospital delirium, and acute stroke, were associated with an increased risk of developing dementia that was higher, as in 2.063-, 2.268-, 5.260-, 5.623-, and 2.086-fold (all $p<0.001$ ). There were no increased risks of overall dementia and individual types of dementia in the diagnostic subgroups of schizophrenia, bipolar disorder, and major depressive disorder (Table 4).

\section{Sensitivity Analysis for the Risk of Dementia After ECT in Fine and Gray's Survival Analysis Model}

We have also analyzed the risk of dementia after ECT in the ECT cohort, within the first 3 years, between 3 and 6 years, and more than 6 years, with the ECT cohort not being associated with the increased risk of dementia (Table 5).
TABLE 2 | Characteristics of study at the end of follow-up.

\begin{tabular}{|c|c|c|c|c|c|}
\hline \multirow{2}{*}{$\begin{array}{l}\text { ECT } \\
\text { variables }\end{array}$} & \multicolumn{2}{|c|}{ With } & \multicolumn{2}{|c|}{ Without } & \multirow[t]{2}{*}{$P$} \\
\hline & $n$ & $\%$ & $n$ & $\%$ & \\
\hline Total & 994 & 25.00 & 2,982 & 75.00 & \\
\hline Dementia & & & & & 0.308 \\
\hline Without & 949 & 95.47 & 2,833 & 95.00 & \\
\hline With & 45 & 4.53 & 149 & 5.00 & \\
\hline Subgroups of dementia & & & & & 0.695 \\
\hline$A D$ & 4 & 0.40 & 7 & 0.23 & \\
\hline VaD & 1 & 0.10 & 3 & 0.10 & \\
\hline Other dementia & 40 & 4.02 & 139 & 4.66 & \\
\hline Study sample subgroup & & & & & 0.999 \\
\hline Schizophrenia & 464 & 46.68 & 1,392 & 46.68 & \\
\hline Bipolar disorders & 117 & 11.77 & 351 & 11.77 & \\
\hline Major depressive disorders & 413 & 41.55 & 1,239 & 41.55 & \\
\hline Gender & & & & & 0.999 \\
\hline Male & 380 & 38.23 & 1,140 & 38.23 & \\
\hline Female & 614 & 61.77 & 1,842 & 61.77 & \\
\hline Age (years) & \multicolumn{2}{|c|}{$46.63 \pm 12.76$} & \multicolumn{2}{|c|}{$44.81 \pm 13.42$} & 0.127 \\
\hline Age group (years) & & & & & 0.167 \\
\hline $20-64$ & 946 & 95.17 & 2,812 & 94.30 & \\
\hline$\geqq 65$ & 48 & 4.83 & 170 & 5.70 & \\
\hline CCl_R & \multicolumn{2}{|c|}{$0.17 \pm 0.78$} & \multicolumn{2}{|c|}{$0.34 \pm 1.18$} & $<0.001$ \\
\hline Spine fractures & 0 & 0 & 9 & 0.30 & 0.075 \\
\hline Non-spine fractures & 23 & 2.31 & 76 & 2.55 & 0.391 \\
\hline Prolonged seizures & 7 & 0.70 & 1 & 0.03 & $<0.001$ \\
\hline Post-ECT delirium/confusions & 2 & 0.20 & 35 & 1.17 & 0.004 \\
\hline \multicolumn{6}{|l|}{ MACEs } \\
\hline AMI & 8 & 0.80 & 28 & 0.94 & 0.847 \\
\hline Acute stroke & 37 & 3.72 & 123 & 4.12 & 0.641 \\
\hline CAD & 59 & 5.94 & 203 & 6.81 & 0.376 \\
\hline Dysrhythmias & 82 & 8.25 & 242 & 8.12 & 0.517 \\
\hline Cardiac shock & 3 & 0.30 & 6 & 0.20 & 0.699 \\
\hline ICD & 3 & 0.30 & 4 & 0.13 & 0.377 \\
\hline SCD & 4 & 0.40 & 8 & 0.27 & 0.509 \\
\hline
\end{tabular}

$P$, Chi-square/Fisher exact test on category variables and t-test on continue variables; $A D$, Alzheimer dementia, VaD, vascular dementia; CCl, Charlson Comorbidity Index; $C A D$, Coronary artery disease; ICD, Ischemic heart disease; SCD, Sudden cardiac death.

\section{DISCUSSION}

In this cohort study, ECT was not associated with the risk of dementia, in the patients' group with schizophrenia, bipolar disorder, and major depressive disorder, or these psychiatric disorders as a whole. This study echoes the findings of the previous study that the ECT is not associated with an increased risk of dementia in the patients with affective disorders (22), and depicted that neither is the ECT associated with the increased risk of dementia in the patients with schizophrenia, for the first 
TABLE 3 | Factors of dementia by using Fine and Gray's competing risk model.

\begin{tabular}{|c|c|c|c|c|c|c|c|c|}
\hline \multirow[t]{2}{*}{ Variables } & \multicolumn{8}{|c|}{ Competing risk in the model } \\
\hline & Crude HR & $95 \% \mathrm{Cl}$ & $95 \% \mathrm{Cl}$ & $\boldsymbol{P}$ & Adjusted HR & $95 \% \mathrm{Cl}$ & $95 \% \mathrm{Cl}$ & $P$ \\
\hline ECT (reference: without) & 0.612 & 0.438 & 1.854 & 0.325 & 0.764 & 0.538 & 1.086 & 0.133 \\
\hline$\geqq 65$ years (reference: $20-64$ years) & 2.667 & 1.797 & 3.958 & $<0.001$ & 2.268 & 1.476 & 3.484 & $<0.001$ \\
\hline CCl_R & 1.100 & 1.027 & 1.177 & 0.006 & 0.992 & 0.896 & 1.099 & 0.882 \\
\hline Non-spine fractures (reference: without) & 0.150 & 0.021 & 1.071 & 0.058 & 0.120 & 0.017 & 0.862 & 0.035 \\
\hline Prolonged seizures (reference: without) & 4.310 & 1.070 & 17.365 & 0.040 & 5.260 & 1.277 & 21.666 & 0.022 \\
\hline Post-ECT delirium/confusions (reference: without) & 7.063 & 4.099 & 12.721 & $<0.001$ & 5.623 & 3.195 & 9.898 & $<0.001$ \\
\hline AMI (reference: without) & 2.589 & 1.148 & 5.839 & $<0.001$ & 2.203 & 0.878 & 5.525 & 0.092 \\
\hline Acute stroke (reference: without) & 2.530 & 1.704 & 3.757 & $<0.001$ & 2.086 & 1.371 & 3.175 & 0.001 \\
\hline ICD (reference: without) & 0 & - & - & 0.646 & 0 & - & - & 0.963 \\
\hline SCD (reference: without) & 8.754 & 2.793 & 27.436 & $<0.001$ & 4.733 & 1.456 & 15.380 & 0.010 \\
\hline
\end{tabular}

HR, hazard ratio; Cl, confidence interval; Adjusted HR: Adjusted for gender, age, comorbidities, urbanization level, location, and insured premium; CCl, Charlson Comorbidity Index; $C A D$, Coronary artery disease; ICD, Ischemic heart disease; SCD, Sudden cardiac death.

TABLE 4 | Factors of dementia subgroup stratified by study sample by using Cox regression and Fine and Gray's competing risk model.

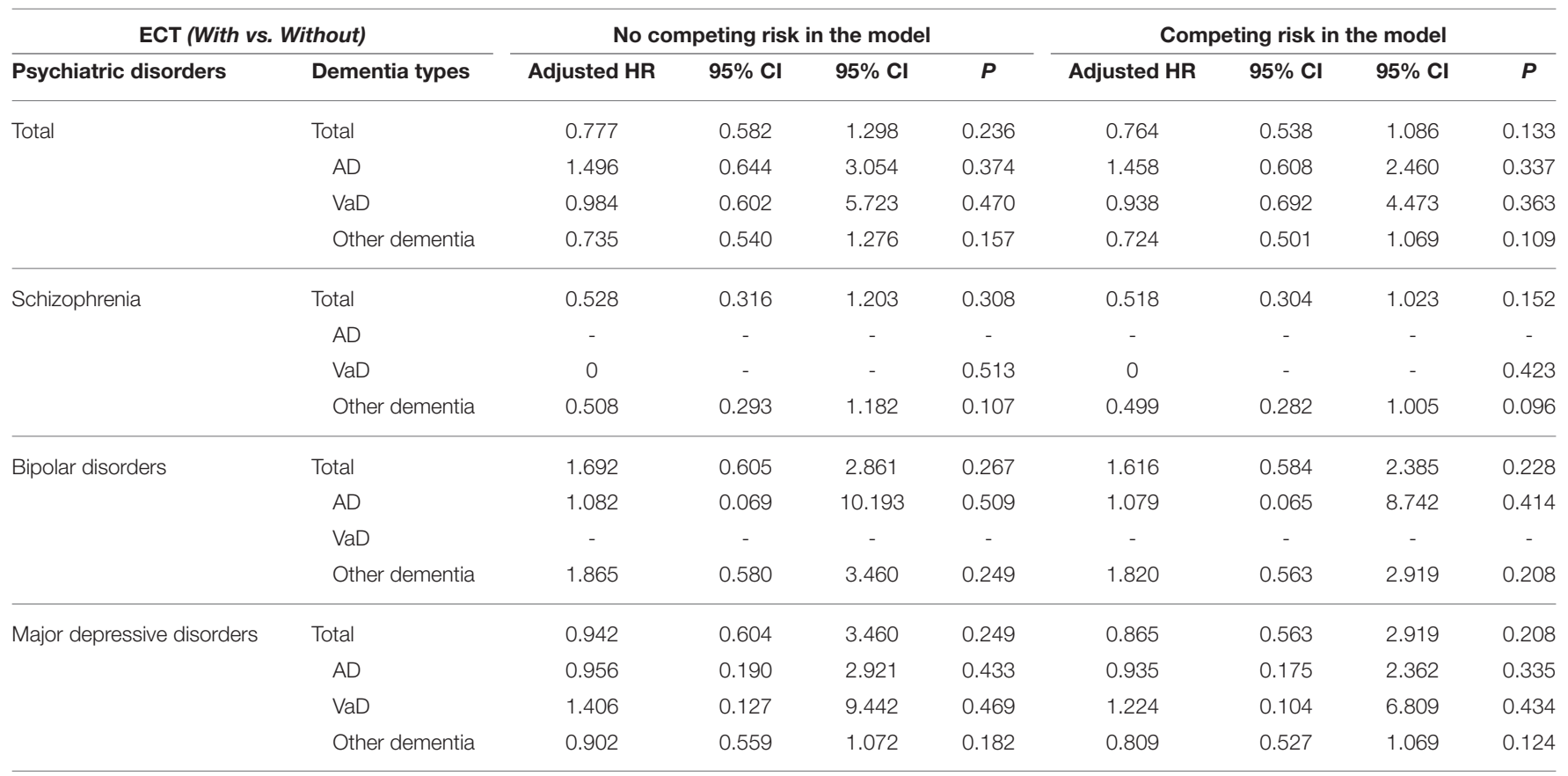

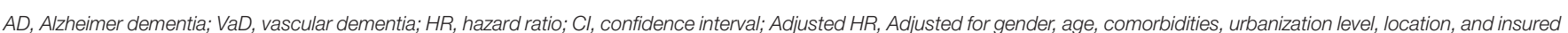
premium.

time. The observation was made that the ECT cohort, within the first 3 years, between 3 and 6 years, and more than 6 years, was not associated with the increased risk of dementia, after conducting a sensitivity analysis that also supported this finding.
The patients who received ECT may display short-term cognitive impairment deficits in the processing speed, executive function, and memory $(2,9,10)$. Two previous studies examined the risk of dementia in older patients with depression following ECT, and the findings showed that the ECT was associated 
TABLE 5 | Sensitivity analysis for the risk of dementia after ECT in Fine and Gray's survival analysis model.

\begin{tabular}{|c|c|c|c|c|c|c|c|}
\hline \multirow[t]{2}{*}{ Tracking interval } & \multirow[t]{2}{*}{ Study sample of subgroups } & \multicolumn{3}{|c|}{ No competing risk in the model } & \multicolumn{3}{|c|}{ Competing risk in the model } \\
\hline & & Adjusted HR & $95 \% \mathrm{Cl}$ & $\boldsymbol{P}$ & Adjusted HR & $95 \% \mathrm{Cl}$ & $\boldsymbol{P}$ \\
\hline \multirow[t]{4}{*}{ Whole period } & Total & 0.777 & $0.582-1.298$ & 0.236 & 0.764 & $0.538-1.086$ & 0.133 \\
\hline & Schizophrenia & 0.528 & $0.316-1.203$ & 0.308 & 0.518 & $0.304-1.023$ & 0.152 \\
\hline & Bipolar disorder & 1.692 & $0.605-2.861$ & 0.267 & 1.616 & $0.584-2.385$ & 0.228 \\
\hline & Major depressive disorder & 0.942 & $0.604-3.460$ & 0.249 & 0.865 & $0.563-2.919$ & 0.208 \\
\hline \multirow[t]{4}{*}{$0-1$ year } & Total & 0.991 & $0.651-1.508$ & 0.264 & 0.971 & $0.638-1.478$ & 0.213 \\
\hline & Schizophrenia & 0.673 & $0.353-1.398$ & 0.297 & 0.660 & $0.346-1.370$ & 0.277 \\
\hline & Bipolar disorder & 2.158 & $0.677-3.324$ & 0.342 & 2.115 & $0.663-3.238$ & 0.322 \\
\hline & Major depressive disorder & 1.201 & $0.676-4.020$ & 0.254 & 1.177 & $0.662-3.940$ & 0.224 \\
\hline \multirow[t]{4}{*}{$3-6$ years } & Total & 1.821 & $0.728-4.556$ & 0.200 & 1.782 & $0.714-4.469$ & 0.198 \\
\hline & Schizophrenia & 1.237 & $0.398-4.224$ & 0.135 & 1.211 & $0.390-4.414$ & 0.112 \\
\hline & Bipolar disorder & 7.635 & $0.837-23.627$ & 0.264 & 7.490 & $0.821-23.178$ & 0.245 \\
\hline & Major depressive disorder & 2.207 & $0.756-12.148$ & 0.346 & 2.165 & $0.742-11.187$ & 0.313 \\
\hline \multirow[t]{4}{*}{$\geqq 6$ years } & Total & 0.685 & $0.513-2.065$ & 0.123 & 0.671 & $0.502-2.024$ & 0.114 \\
\hline & Schizophrenia & 0.462 & $0.278-1.060$ & 0.377 & 0.452 & $0.272-1.038$ & 0.376 \\
\hline & Bipolar disorder & 1.491 & $0.533-2.521$ & 0.277 & 1.460 & $0.522-2.486$ & 0.273 \\
\hline & Major depressive disorder & 0.803 & $0.532-3.048$ & 0.298 & 0.813 & $0.521-2.984$ & 0.288 \\
\hline
\end{tabular}

HR, hazard ratio; Cl, confidence interval; Adjusted HR: Adjusted for gender, age, comorbidities, urbanization level, location, and insured premium.

with an increased risk of dementia; however, these two studies enrolled relatively small sample sizes $(N=81$, and $N=47$, respectively) $(37,38)$. In our study, the risk of dementia in patients did not increase with schizophrenia, bipolar disorder, and major depressive disorders following ECT. One Danish cohort study found that there was no association between ECT and the risk in patients with affective disorders (22). However, in our study, we not only examined the association between patients with affective disorders but also schizophrenia, and the risk of dementia following ECT.

In this study, we did not find any deaths from ECT, in comparison to one previous 17-year nationwide populationbased retrospective study in Taiwan, which showed that the inhospital death rate of patients who received ECT was $0.19 \%$ (8). Other studies presented that ECT-related deaths were either very low or none at all (5-7). The ECT cohort with prolonged seizures $(39,40)$, post-ECT in-hospital delirium (41), and MACE's (9), were complications of ECT. Our study found that these prolonged seizures in-hospital, post-ECT in-hospital delirium, and acute stroke were associated with an increased risk of dementia for the ECT cohort. This could serve as a reminder to the psychiatrists and/or other physicians to screen the risk of these complications before ECT, and be watchful when followingup the ECT patients that have experienced these complications. In addition, older patients and male patients who have received ECT also need careful follow-up.

The ECT has been shown to stimulate neurogenesis, giving rise to the hypothesis that this generation of new cells mediates some of their therapeutic effect (42). The ECT could also induce neuroplasticity, and even increase the volumes in the hippocampus, amygdala, and the regions with prominent connections to the ventromedial prefrontal cortex, and other limbic structures in patients with major depressive disorder (43). For treatment-resistant schizophrenia, the ECT significantly increased the vascular endothelial growth factor, thus, leading to stimulating the neurogenesis in the brain (44). In animal models, the ECT could also provide the neurogenetic effects not only at the hippocampus but also at the frontal brain areas (45). Generally, ECT had a neurogenetic ability and this could be the reason for these patients to preserve their cognitive function after the ECT.

\section{Strengths of This Study}

There are several strengths of this study: First, the diagnoses were based on the ICD-9 codes, and several previous studies have demonstrated the accuracy and validity of some diagnoses in the NHIRD, including diabetes mellitus $(46,47)$, cancer $(33$, $46,48)$, myocardial infarction $(46,49,50)$, Tourette syndrome (32), stroke $(31,46,51,52)$, pneumonia (53), sleep apnea (53), pulmonary tuberculosis $(54,55)$, chronic obstructive pulmonary disease (56), and asthma (56). In addition, the outcomes (46), mortality $(46,51)$, or comorbidity $(46,51)$ were also valid in the NHIRD. Some other studies even depicted the concordance between Taiwan's National Health Survey, another health databank, and the NHIRD on a variety of diagnoses (57), medication usage (57), and health system utilizations $(57,58)$.

Furthermore, the cumulative incidence rates of dementia were $4.53 \%$ in the ECT cohort, and $5.0 \%$ in the control group, which were close to a previous survey of the nationwide prevalence of dementia in Taiwan (59). Therefore, we propose that this 
selected population should be considered as a representative for this type of study. Correspondingly, the long-term observation period from 2000 to 2010 allowed for more credibility.

\section{LIMITATIONS}

Several limitations should be considered in this study. First, the longest course of our study was followed for only 10 years, and the dementia was a very late onset disease, with the risk being accumulated more in the geriatric patients. This study, therefore, cannot represent the dementia risk in the elderly patients. Second, like many previous NHIRD based studies, they are retrospective and dependent upon the ICD-9-CM codes instead of a direct medical record or the interview data. Therefore, lack of detailed records and misdiagnosis related errors may well occur. Third, this national insurance database cannot provide detailed information that includes the severity of the disease as well as the minor complications. Fourth, in this study, there were three different psychiatric diagnoses groups, therefore we have limitations in the eliminations of the impacts of different diagnoses. Even though we have conducted the analysis of baseline characteristics of the patients with schizophrenia, bipolar disorder, and major depressive disorder (Supplementary Table 1), and the overall or ECT-related readmission rates (Supplementary Table 2), the limitations still exist. However, in the sensitivity test (Table 5), we could also find that the difference of diagnoses with ECT showed no significant impacts on the results, based on the observation that each diagnosis was not associated with the risk of dementia at different time period ( $0-1,3-6$, $\geqq 6$ years) after the ECT. Finally, even though only newly diagnosed dementia would be included in the follow-up period, a protopathic bias, in which the initiation of an exposure occurs in response to an undiagnosed disease (outcome) under study (60), should also be considered since some of the participants in the ECT cohort suffered from cognitive decline before their suicide attempts. However, we have done a sensitivity test as shown in Table 5, which also showed no association between the risk of dementia and ECT.

\section{REFERENCES}

1. Lisanby SH. Electroconvulsive therapy for depression. New Engl J Med. (2007) 357:1939-45. doi: 10.1056/NEJMct075234

2. Tess AV, Smetana GW. Medical evaluation of patients undergoing electroconvulsive therapy. New Engl J Med. (2009) 360:1437-44. doi: 10.1056/NEJMra0707755

3. Glenisson L, Auriacombe M, Fernandez T, Auriacombe S, Gomez F, Uzandisaga D, et al. [Adverse seizure reactions after electroconvulsive therapy. Study of personal cases and review of the literature]. L'Encephale (1998) 24:1-8.

4. Dighe-Deo D, Shah A. Electroconvulsive therapy in patients with long bone fractures. J ECT (1998) 14:115-9. doi: 10.1097/00124509-19980600000009

5. Shiwach RS, Reid WH, Carmody TJ. An analysis of reported deaths following electroconvulsive therapy in Texas, 1993-1998. Psychiatr Serv. (2001) 52:10957. doi: 10.1176/appi.ps.52.8.1095

\section{CONCLUSION}

There is strong evidence to support that the ECT was not associated with the risk of dementia for patients with schizophrenia, bipolar disorders, and major depressive disorders. Our study also found that the ECT cohort with prolonged seizures in-hospital, post-ECT in-hospital delirium, and acute stroke were associated with the increased risk of dementia for the ECT cohort. This could serve as a reminder to the psychiatrists and/or other physicians to screen the risk of these complications before ECT, and be watchful in following-up the ECT patients that have experienced these complications.

\section{AUTHOR CONTRIBUTIONS}

C-WC, W-CC, and N-ST conceived, designed, and conducted this study. W-CC, C-HC, and P-CC conducted data collection, statistical analysis and interpretation. $\mathrm{H}-\mathrm{AC}, \mathrm{Y}-\mathrm{CK}$, and $\mathrm{Y}-$ CC contributed in the data interpretation, C-WC wrote the manuscript. All authors approved this manuscript.

\section{FUNDING}

This study was funded by the Tri-Service General Hospital Research Foundation (TSGH-C105-130, TSGH-C106-002, TSGH-C106-106, andTSGH-C107-004), and the Medical Affairs Bureau, Ministry of Defense of Taiwan (MAB-107-084).

\section{ACKNOWLEDGMENTS}

We would like to show our appreciation to Chang-Huei Tsao, Ph.D., and Yung-Fu Wu, for their proofreading and contributions in this paper's work.

\section{SUPPLEMENTARY MATERIAL}

The Supplementary Material for this article can be found online at: https://www.frontiersin.org/articles/10.3389/fpsyt. 2018.00397/full\#supplementary-material

6. Nuttall GA, Bowersox MR, Douglass SB, McDonald J, Rasmussen LJ, Decker $\mathrm{PA}$, et al. Morbidity and mortality in the use of electroconvulsive therapy. $J$ ECT (2004) 20:237-41. doi: 10.1097/00124509-200412000-00009

7. Munk-Olsen T, Laursen TM, Videbech P, Mortensen PB, Rosenberg R. All-cause mortality among recipients of electroconvulsive therapy: register-based cohort study. Br J Psychiatry (2007) 190:435-9. doi: 10.1192/bjp.bp.106.026740

8. Liang CS, Chung $\mathrm{CH}$, Tsai $\mathrm{CK}$, Chien WC. In-hospital mortality among electroconvulsive therapy recipients: a 17-year nationwide population-based retrospective study. Eur Psychiatry (2017) 42:29-35. doi: 10.1016/j.eurpsy.2016.12.005

9. Andrade C, Arumugham SS, Thirthalli J. Adverse effects of electroconvulsive therapy. Psychiatr Clin North Am. (2016) 39:513-30. doi: 10.1016/j.psc.2016.04.004

10. Group UER. Efficacy and safety of electroconvulsive therapy in depressive disorders: a systematic review and meta-analysis. Lancet (2003) 361:799-808. doi: 10.1016/S0140-6736(03)12705-5 
11. Leiknes KA, Jarosh-von Schweder L, Hoie B. Contemporary use and practice of electroconvulsive therapy worldwide. Brain Behav. (2012) 2:283-344. doi: $10.1002 /$ brb3.37

12. World Health Organization. Dementia Cases Set to Triple by 2050 But Still Largely Ignored. (2012) Available online at: http://www.who.int/mediacentre/ news/releases/2012/dementia_20120411/en/index.html.

13. Fuh JL, Wang SJ. Dementia in Taiwan: past, present, and future. Acta Neurol Taiwan. (2008) 17:153-61.

14. Taiwan Alzheimer's Disease Association. 2015-2056 Expected Dementia popultion Report in Taiwan: Taiwan Alzheimer's Disease Association. (2013) Available online at: http://www.tada2002.org.tw/tada_know_02.html\#01.

15. Tzeng NS, Chang CW, Hsu JY, Chou YC, Chang HA, Kao YC. Caregiver burden for patients with dementia with or without hiring foreign health aides: a cross-sectional study in a northern taiwan memory clinic. J Med Sci. (2015) 35:239-47. doi: 10.4103/1011-4564.172999

16. Chao PC, Chien WC, Chung $\mathrm{CH}$, Chu CW, Yeh CB, Huang SY, et al. Cognitive enhancers associated with decreased risk of injury in patients with dementia: a nationwide cohort study in Taiwan. J Invest Med. (2018) 66:684-92. doi: 10.1136/jim-2017-000595

17. Wang HY, Chen JH, Huang SY, Yeh HW, Mao WC, Chang HA, et al. Forensic evaluations for offenders with dementia in Taiwan's criminal courts. J Am Acad Psychiatry Law (2018) 46:45-51.

18. Muramatsu T, Kato M, Matsui T, Yoshimasu H, Yoshino A, Matsushita S, et al. Apolipoprotein E epsilon 4 allele distribution in Wernicke-Korsakoff syndrome with or without global intellectual deficits. J Neural Transm. (1997) 104:913-20. doi: 10.1007/BF01285559

19. Ridley NJ, Draper B, Withall A. Alcohol-related dementia: an update of the evidence. Alzheimer Res Therapy (2013) 5:3. doi: 10.1186/alzrt157

20. Kao LC, Chien WC, Chung CH, Yeh HW, Chou YC, Huang SY, et al. The association between newly-diagnosed amnestic disorders and dementia: a nationwide, population-based, historical cohort study in Taiwan. Taiwanese J Psychiatry (2018) 32:18-28.

21. Weiner RD, Reti IM. Key updates in the clinical application of electroconvulsive therapy. Int Rev Psychiatry (2017) 29:54-62. doi: 10.1080/09540261.2017.1309362

22. Osler M, Rozing MP, Christensen GT, Andersen PK, Jorgensen MB. Electroconvulsive therapy and risk of dementia in patients with affective disorders: a cohort study. Lancet Psychiatry (2018) 5:348-56. doi: 10.1016/S2215-0366(18)30056-7

23. Ho Chan WS. Taiwan's healthcare report 2010. EPMA J. (2010) 1:563-85. doi: 10.1007/s13167-010-0056-8

24. Chinese Hospital Association. ICD-9-CM English-Chinese Dictionary. Taipei: Chinese Hospital Association Press (2000).

25. Tzeng NS, Chung $\mathrm{CH}$, Lin FH, Chiang CP, Yeh CB, Huang SY, et al. Anti-herpetic medications and reduced risk of dementia in patients with herpes simplex virus infections-a nationwide, populationbased cohort study in Taiwan. Neurotherapeutics (2018). 15:417-29. doi: 10.1007/s13311-018-0611-x

26. Tzeng NS, Chung CH, Lin FH, Huang CF, Yeh CB, Huang SY, et al. Magnesium oxide use and reduced risk of dementia: a retrospective, nationwide cohort study in Taiwan. Curr Med Res Opin. (2018) 34:163-9. doi: 10.1080/03007995.2017.1385449

27. Tzeng NS, Chung CH, Lin FH, Yeh CB, Huang SY, Lu RB, et al. Headaches and risk of dementia. Am J Med Sci. (2017) 353:197-206. doi: 10.1016/j.amjms.2016.12.014

28. Tzeng NS, Chung CH, Lin FH, Yeh CB, Huang SY, Lu RB, et al. Risk of Dementia in adults with ADHD: a nationwide, population-based cohort study in Taiwan. J Atten Disord. (2017). 1:1087054717714057. doi: 10.1177/1087054717714057

29. Chien WC, Chung CH, Lin FH, Chang HA, Kao YC, Tzeng NS. Is weight control surgery associated with increased risk of newly onset psychiatric disorders? A population-based, matched cohort study in Taiwan. J Med Sci. (2017) 37:137-49. doi: 10.4103/jmedsci.jmedsci_94_16

30. Ministry of Justice. National Health Insurance Regulations (2014) Available online at: http://law.moj.gov.tw/LawClass/LawAllIf.aspx?PCode=L0060006.

31. Cheng CL, Kao YH, Lin SJ, Lee CH, Lai ML. Validation of the National Health Insurance Research Database with ischemic stroke cases in Taiwan. Pharmacoepidemiol Drug Safety (2011) 20:236-42. doi: 10.1002/ pds. 2087
32. Chou IC, Lin HC, Lin CC, Sung FC, Kao CH. Tourette syndrome and risk of depression: a population-based cohort study in Taiwan. J Dev Behav Pediatr. (2013) 34:181-5. doi: 10.1097/DBP.0b013e3182829f2b

33. Liang JA, Sun LM, Muo CH, Sung FC, Chang SN, Kao CH. The analysis of depression and subsequent cancer risk in Taiwan. Cancer Epidemiol Biomarkers Prev. (2011) 20:473-5. doi: 10.1158/1055-9965.EPI-10-1280

34. Chang CY, Chen WL, Liou YF, Ke CC, Lee HC, Huang HL, et al. Increased risk of major depression in the three years following a femoral neck fracturea national population-based follow-up study. PLoS ONE (2014) 9:e89867. doi: 10.1371/journal.pone.0089867

35. Charlson ME, Pompei P, Ales KL, MacKenzie CR. A new method of classifying prognostic comorbidity in longitudinal studies: development and validation. $J$ Chronic Dis. (1987) 40:373-83. doi: 10.1016/0021-9681(87)90171-8

36. American Psychiatric Association. Diagnostic and Statistical Manual of Mental disorders (4th ed), Text Revision. Washington, DC: American Psychiatric Association (2000).

37. Brodaty H, Hickie I, Mason C, Prenter L. A prospective follow-up study of ECT outcome in older depressed patients. J Affect Disord. (2000) 60:101-11. doi: 10.1016/S0165-0327(99)00169-X

38. Berggren A, Gustafson L, Hoglund P, Johanson A. A long-term longitudinal follow-up of depressed patients treated with ECT with special focus on development of dementia. J Affect Disord. (2016) 200:15-24. doi: 10.1016/j.jad.2016.04.004

39. Cristancho MA, Alici Y, Augoustides JG, O'Reardon JP. Uncommon but serious complications associated with electroconvulsive therapy: recognition and management for the clinician. Curr Psychiatry Rep. (2008) 10:474-80. doi: 10.1007/s11920-008-0076-4

40. Pogarell O, Ehrentraut S, Ruther T, Mulert C, Hegerl U, Moller HJ, et al. Prolonged confusional state following electroconvulsive therapy-diagnostic clues from serial electroencephalography. Pharmacopsychiatry (2005) 38:31620. doi: 10.1055/s-2005-916187

41. Hassamal S, Pandurangi A, Venkatachalam V, Levenson J. Delayed Onset and Prolonged ECT-Related Delirium. Case Rep Psychiatry (2013) 2013:840425. doi: $10.1155 / 2013 / 840425$

42. Ongur D, Heckers S. A role for glia in the action of electroconvulsive therapy. Harvard Rev Psychiatry (2004) 12:253-62. doi: 10.1080/10673220490886185

43. Joshi SH, Espinoza RT, Pirnia T, Shi J, Wang Y, Ayers B, et al. Structural plasticity of the hippocampus and amygdala induced by electroconvulsive therapy in major depression. Biol Psychiatry (2016) 79:28292. doi: 10.1016/j.biopsych.2015.02.029

44. Xiao W, Zhan Q, Ye F, Tang X, Li J, Dong H, et al. Elevated serum vascular endothelial growth factor in treatment-resistant schizophrenia treated with electroconvulsive therapy: positive association with therapeutic effects. World J Biol Psychiatry (2018) 26:1-9.

45. Inta D, Lima-Ojeda JM, Lau T, Tang W, Dormann C, Sprengel R, et al. Electroconvulsive therapy induces neurogenesis in frontal rat brain areas. PLoS ONE (2013) 8:e69869. doi: 10.1371/journal.pone.0069869

46. Cheng CL, Chien HC, Lee CH, Lin SJ, Yang YH. Validity of in-hospital mortality data among patients with acute myocardial infarction or stroke in National Health Insurance Research Database in Taiwan. Int J Cardiol. (2015) 201:96-101. doi: 10.1016/j.ijcard.2015.07.075

47. Lin CC, Lai MS, Syu CY, Chang SC, Tseng FY. Accuracy of diabetes diagnosis in health insurance claims data in Taiwan. J Formos Med Assoc. (2005) 104:157-63.

48. Li-Ting C, Chung-Ho C, Yi-Hsin Y, Pei-Shan H. The development and validation of oral cancer staging using administrative health data. BMC Cancer (2014) 14:380. doi: 10.1186/1471-2407-14-380

49. Cheng CL, Lee CH, Chen PS, Li YH, Lin SJ, Yang YH. Validation of acute myocardial infarction cases in the national health insurance research database in taiwan. J Epidemiol. (2014) 24:500-7. doi: 10.2188/jea.JE20 140076

50. Hsieh CY, Chen CH, Li CY, Lai ML. Validating the diagnosis of acute ischemic stroke in a National Health Insurance claims database. J Formos Med Assoc. (2015) 114:254-9. doi: 10.1016/j.jfma.2013.09.009

51. Sung SF, Hsieh CY, Lin HJ, Chen YW, Yang YH, Li CY. Validation of algorithms to identify stroke risk factors in patients with acute ischemic stroke, transient ischemic attack, or intracerebral hemorrhage in an administrative claims database. Int J Cardiol. (2016) 215:277-82. doi: 10.1016/j.ijcard.2016.04.069 
52. Tseng HP, Lin FJ, Chen PT, Mou CH, Lee SP, Chang CY, et al. Derivation and validation of a discharge disposition predicting model after acute stroke. J Stroke Cerebrovasc Dis. (2015) 24:1179-86. doi: 10.1016/j.jstrokecerebrovasdis.2015.01.010

53. Su VY, Liu CJ, Wang HK, Wu LA, Chang SC, Perng DW, et al. Sleep apnea and risk of pneumonia: a nationwide population-based study. CMAJ (2014) 186:415-21. doi: 10.1503/cmaj.131547

54. Su VY, Yen YF, Pan SW, Chuang PH, Feng JY, Chou KT, et al. Latent tuberculosis infection and the risk of subsequent cancer. Medicine (2016) 95:e2352. doi: 10.1097/MD.0000000000002352

55. Lee MY, Lin KD, Hsu WH, Chang HL, Yang YH, Hsiao PJ, et al. Statin, calcium channel blocker and Beta blocker therapy may decrease the incidence of tuberculosis infection in elderly Taiwanese patients with type 2 diabetes. Int J Mol Sci. (2015) 16:11369-84. doi: 10.3390/ijms160511369

56. Su VY, Yang KY, Yang YH, Tsai YH, Perng DW, Su WJ, et al. Use of ICS/LABA Combinations or LAMA Is Associated with a lower risk of acute exacerbation in patients with coexistent COPD and Asthma. J Allergy Clin Immunol Pract. (2018). doi: 10.1016/j.jaip.2018.01.035. [Epub ahead of print].

57. Wu CS, Lai MS, Gau SS, Wang SC, Tsai HJ. Concordance between patient self-reports and claims data on clinical diagnoses, medication use, and health system utilization in Taiwan. PLOS ONE (2014) 9:e112257. doi: 10.1371/journal.pone.0112257
58. Yu ST, Chang HY, Lin MC, Lin YH. Agreement between self-reported and health insurance claims on utilization of health care: a population study. J Clin Epidemiol. (2009) 62:1316-22. doi: 10.1016/j.jclinepi.2009. 01.016

59. Sun Y, Lee HJ, Yang SC, Chen TF, Lin KN, Lin CC, et al. A nationwide survey of mild cognitive impairment and dementia, including very mild dementia, in Taiwan. PLoS ONE (2014) 9:e100303. doi: 10.1371/journal.pone.01 00303

60. Gerhard T. Bias: considerations for research practice. Am J Health Syst Pharmacy (2008) 65:2159-68. doi: 10.2146/ajhp070369

Conflict of Interest Statement: The authors declare that the research was conducted in the absence of any commercial or financial relationships that could be construed as a potential conflict of interest.

Copyright (c) 2018 Chu, Chien, Chung, Chao, Chang, Kao, Chou and Tzeng. This is an open-access article distributed under the terms of the Creative Commons Attribution License (CC BY). The use, distribution or reproduction in other forums is permitted, provided the original author(s) and the copyright owner(s) are credited and that the original publication in this journal is cited, in accordance with accepted academic practice. No use, distribution or reproduction is permitted which does not comply with these terms. 